Applied Physiology, Nutrition, and Metabolism

Canadian Science Publishing Physiologie appliquée, nutrition et métabolisme

\title{
Evaluation of the Get Active Questionnaire in Community- Dwelling Older Adults
}

\begin{tabular}{|r|l|}
\hline Journal: & Applied Physiology, Nutrition, and Metabolism \\
\hline Manuscript ID & apnm-2017-0489.R3 \\
\hline Manuscript Type: & Article \\
\hline Date Submitted by the Author: & 08-Nov-2017 \\
\hline Complete List of Authors: & $\begin{array}{l}\text { Petrella, Andrea; Western University, Kinesiology } \\
\text { Gill, Dawn; The University of Western Ontario, Family Medicine } \\
\text { Petrella, Robert; Western University, Centre for Studies in Family Medicine, } \\
\text { Department of Family Medicine }\end{array}$ \\
\hline Keyword: & $\begin{array}{l}\text { physical activity < exercise, stress test, aging, self screening, physical } \\
\text { activity screening }\end{array}$ \\
\hline $\begin{array}{r}\text { Is the invited manuscript for } \\
\text { consideration in a Special } \\
\text { Issue? : }\end{array}$ & N/A \\
\hline
\end{tabular}


3

Andrea F. M. Petrella, MSc Candidate

4 Faculty of Health Sciences, School of Kinesiology, Western University

5 London, ON, N6A 3K7

6 apetrel4@uwo.ca

7

8 Dawn P. Gill, PhD

9 Centre for Studies in Family Medicine, Department of Family Medicine, Western University

10 Faculty of Health Sciences, School of Health Studies, Western University

11 London, ON, N6G 2M1

12 dawn.gill@uwo.ca

13

14 Corresponding Author:

15 Robert J. Petrella, MD, PhD

16

Centre for Studies in Family Medicine, Department of Family Medicine, Western University

17

Faculty of Health Sciences, School of Kinesiology, Western University

18

London, ON, N6A 2B7

19

519-661-2037

20 petrella@uwo.ca 


\section{Abstract}

24 Background: Physical activity screening prior to starting a physical activity program is important to identify 25 if there are any underlying health conditions. However, many older adults do not complete such 
48 Introduction

49

Evolving pre-participation physical activity screening recommendations seek to simplify the screening

50 process and mitigate potential barriers to adopting a physically active lifestyle (Riebe, 2015). One barrier

51 identified is the high rate of false-positive physical activity tests. To address this potential barrier, the Canadian

52 Society for Exercise Physiology (CSEP) assembled an expert group to develop a new physical activity readiness

53 assessment tool that is user-friendly, evidence-based, and seeks to safely encourage and 'screen-in' as many

54 people as possible to regular healthful physical activity (http://www.csep.ca/home). As such, it is important to

55 promote physical activity for older adults to maintain and improve health outcomes in this population (Nelson

56 et al., 2007). However, there is a small risk of adverse events in some populations. Over $80 \%$ of Canadians

57 greater than 65 years of age have one or more chronic condition (Gilmour and Park, 2006). It has been

58 suggested that existing physical activity screening tools are ineffective in correctly identifying the extremely

59 small number of individuals (often older adults) who are at risk for sudden death during exercise (Morey and

60 Sullivan, 2003; Goodman et al., 2016) and are also associated with high false positive results; potentially

61 exposing older adults to further unnecessary testing, undue stress; potentially negatively impacting physical

62 activity participation (Gill et al., 2000). A recent systematic review (Doma et al., 2017) indicated the limitations

63 of current physical activity screening tools after observing poor psychometric properties throughout physical

64 activity questionnaires. Therefore, and not surprisingly, there is a need for user-friendly physical activity

65 screening tools that can both identify exercise-related risk factors and facilitate the safe exercise participation

66 by older adults (Petrella and Wight, 2000; Resnick et al., 2008; Chodzko-Zajko et al., 2009). Medical clearance

67 prior to physical activity participation has been recommended for adults regardless of risk status (Eves and

68 Davidson, 2011). As physical activity screening tools continue to be revised (i.e., the Physical Activity Readiness

69 Questionnaire $(\mathrm{PARQ}+)$ demonstrated a reduced number of exclusions in older adults), there is insufficient data

$\mathbf{7 0}$ to exclude any specific age-group from physical activity (Goodman et al., 2016). Further, most physical activity

71 screening tools do not provide instructions or a suggested age-range of users. In addition, older adult memory 
72 recall while completing questionnaires has been found to have inconsistent reliability and validity findings

73 (Forsen et al., 2010). Thus, older adults may have unique risk factors and/or have a distinct interpretation of

74 pre-physical activity screening tools. Therefore, the purpose of this study was to evaluate the psychometric

75 properties (test-retest reliability and criterion-related validity) of the newly developed Get Active

76 Questionnaire (GAQ) in community-dwelling in older adults.

\section{Materials \& Methods}

\section{Ethics}

80 Committee for Research on Human Subjects (Protocol \#108058). Each volunteer provided written, informed 81 consent prior to participation in the study.

\section{Setting}

Data collection, administration of the GAQ, and stress testing took place at the research laboratory at

84 the Western Centre for Public Health and Family Medicine, Western University, London, Ontario. The

85 laboratory routinely conducts physical activity screening for community-based referrals.

\section{Sample}

87

A convenience sample of community-dwelling adults (male $n=58$, female $n=54$ ) aged $75 \pm 7$ years in the

88 City of London, Ontario was used. All individuals over 50 years of age who presented to the lab for either an

89 annual physical activity program stress test or prior to beginning a physical activity program at the Canadian

90 Center for Activity and Aging or the Retirement Research Association at Western University were eligible for

91 the study. Recruitment was conducted by the stress test assistant. Exclusion criteria included a score less than

9224 on the Mini Mental State Examination (MMSE) and those living in institutional settings, such as nursing

93 homes or chronic care facilities. 
95 The sample size calculation for the test-retest reliability was calculated to be 80 , based on the 96 approximation of intraclass correlations (ICC) (with Fisher's z transformation) and using a confidence interval of 970.05 and a reliability coefficient of 0.90 (Streiner and Norman, 1995). A recruitment size goal of 120

98 participants was used to account for an anticipated $20 \%$ non-responsive rate. The sample size for validity 99 assessment included all participants completing the GAQ. Data collection took place over a seven-month period (June-December 2016). Participants were asked

101

102

103

104

105

106

107

108

109

110

111

112

113

114

115

116

117

118 to participate in two sessions. On the first day, participants self-completed the GAQ in the presence of the stress test technician/research assistant and then underwent a stress test. The first day (i.e., session one) was estimated to take approximately one hour. Seven days later, participants returned to the laboratory to complete the self-completed GAQ a second time. One week was determined to be of sufficient duration whereby participants were unlikely to recall their previous responses and there was a low risk of additional adverse event occurrence during this period.

\section{Stress Test Assessment}

Participants underwent pre-stress test assessments for self-reported health status, anthropometrics, resting blood pressure, cognition (Mini-Mental Status Examination [MMSE] and Montreal Cognitive Assessment [MoCA]) and recent self-reported health status (diagnosed conditions, medication use, etc.). Participants then underwent a graded-exercise treadmill test. Post-stress test, participants were given the results (and compared to age-matched normative data) and provided a training heart rate to guide their exercise intensity during their physical activity program.

\section{Get Active Questionnaire}

The GAQ is a two-page document consisting of four questions on the first page with direction to assess current physical activity and advice to proceed onto page two. A second, 'Reference Document' is intended to provide advice on what to do in the case of a 'Yes' response to the questionnaire. The GAQ was developed by an expert panel from a CSEP member survey to be administered via paper version to the general public (of all 
119 ages) independently, and/or administered by qualified exercise professionals and healthcare providers

120 (http://www.csep.ca/home).

\section{Statistical Analyses}

122

123 124 percentages were calculated for categorical variables. For all analyses, interpretation of results was primarily

Descriptive statistics were calculated for all variables of interest prior to conducting the main analyses.

Specifically, means and standard deviations were calculated for continuous variables and frequency counts and

125 based on estimation and associated 95\% confidence intervals (Cls); two-sided P values less than 0.05 were reported as statistically significant. Analyses were performed using SAS version 9.4 (SAS Institute Inc., Cary,

127 NC). The following reliability and validity analyses were conducted with visit one data.

128

129

130

131

132

133

134

135

136

137

138

139

140

141

\section{Test-retest Reliability of GAQ Items}

Test-retest reliability refers to agreement among measurements on the same participants at different time points (Koepsell and Weiss, 2003). For all categorical (binary) variables from the GAQ, including the

"Preparing to Become More Active" questions, the "Declaration" items and the "Reference Document" questions, test-retest reliability was assessed using the kappa statistic $(\kappa)$ and associated $95 \% \mathrm{Cls}$ (Cohen, 1960). For continuous variables from the GAQ, which included the "Assess your Current Physical Activity" questions (Table 1), test-retest reliability was assessed using intraclass correlation coefficients (ICCs) and 95\% Cls obtained with Fisher's $z$ transformation (Donner and Zou, 2002). Guidelines from Landis and Koch (1977) were used for interpreting the strength of agreement for kappa values and intraclass correlation coefficients. Exact p-values were calculated for both kappa and ICC statistics.

\section{Risk Level Assignment}

A self-screen variable (i.e., 'screen in' vs. 'screen out') was derived from the GAQ and this was compared with a screening variable that was derived from objectively measured items from the stress test (also coded as 'screen in' vs. 'screen out'). A 'screen in' could indicate an individual could safely proceed to 
142 become more physically active or continue with physical activity; in contrast, a 'screen out' indicates that an

143 individual should not proceed with becoming more physically active or continuing with physical activity until

144 further consultation (i.e., with a healthcare provider (HCP) or a qualified exercise professional (QEP)).

145 For the self-screen variable derived from the GAQ, the declaration questions were used to determine

146 'screen in' versus 'screen out' status. An individual was classified as a 'screen out' if they checked any of the

147 following two possible responses to the Declaration section of the GAQ (note: 'questions' always refer to the

148 questions listed on page one of the GAQ):

149 1) I answered YES to any question and I have not consulted a Health Care Provider (HCP) or Qualified Exercise Professional (QEP) about becoming more physically active; or

2) I would like to consult a QEP about becoming more physically active.

152

In contrast, an individual would be classified as a 'screen in' if they checked any of the following three

153

154

155

156

157

158

159

160

161

162

163

164

165

166

possible responses to the Declaration:

1) I answered NO to all questions;

2) I answered YES to any question and I have consulted a HCP and/or QEP who has recommended I become more physically active; or

3) I am comfortable with becoming more physically active on my own without consulting a HCP and/or QEP.

Note: the item 'I am comfortable with becoming more physically active on my own without consulting a HCP and/or QEP' superseded any other responses (i.e., if this was selected then the individual was automatically classified as a 'screen in').

For the stress test-determined screen variable, several objective items were used to determine 'screen in'/'screen out' status. An individual was classified as a 'screen out' if any of the following were indicated:

1) Heart problems reported to technician prior to stress test (i.e., chest pain, tightness or angina);

2) Individual did not proceed with a stress test or had a non-normal stress test (i.e., results from stress test were equivocal, abnormal, inconclusive or other significant findings were noted); 
167

168

169

170

171

172

173

174

175

176

177

178

179

180

181

182

183

184

185

186

187

188

189

190

191

3) Stopping the stress test for any of the following reasons: lightheaded/dizzy, chest pain, physician's discretion, ECG changes, hypertension, or hypotension;

4) Hypertension (defined as systolic blood pressure, $\mathrm{BP} \geq 180 \mathrm{mmHg}$ and/or diastolic $\mathrm{BP} \geq 110 \mathrm{mmHg}$ ) observed based on average of BP measurements taken during the stress test (including $2^{\text {nd }}$ and $3^{\text {rd }}$ measurements at rest plus post-stress test recovery BP measurements taken at 2 minutes, 4 minutes, 6 minutes, 8 minutes, and 10 minutes post-stress test) (Bloodpressureuk.org, n.d.); or

5) Hypotension (defined as SBP $<100 \mathrm{mmHg}$ and/or DBP $<60 \mathrm{mmHg}$ ) observed based on the same measurements used to determine hypertension.

After the GAQ self-screen and stress test-determined screen variables were created, a two by two table was generated to evaluate the performance of the self-screening via the GAQ versus the stress test-

determined physical activity screening. The exercise stress test has been deemed as the gold standard

measurement for cardiorespiratory fitness (Lafountain et al., 2016). From a two by two table (Table 2), the each variable was to be examined (Koepsell and Weiss, 2003).

\section{GAQ Item Validation}

The same approach outlined above for evaluating the GAQ as a physical activity screening tool was

taken to evaluate validity of two individual items from the GAQ (Questions $1 \mathrm{~A}$ and $1 \mathrm{~B}$ ) related to cardiovascular disease. Question 1A from the GAQ ("Have you experienced ANY of the following within the past six months?...

A diagnosis of heart disease or stroke, or pain/discomfort/pressure in your chest during activities of daily living or during physical activity?) was compared against a derived variable from the stress tests that indicated chest pain or ECG changes as a reason for having to stop the stress test. Question 1B from the GAQ ("Have you experienced ANY of the following within the past six months?... A diagnosis of high blood pressure (BP) and/or a resting BP of $160 / 90 \mathrm{mmHg}$ or higher?") was compared with a derived variable from the stress tests that indicated if someone had high blood pressure per whether they had a measured BP of $\geq 160 / 90 \mathrm{mmHg}$ (taken from the average calculated from the second and third BP readings done at rest) or reported taking a blood pressure medication. 
192

193

194

195

196

197

198

199

200

201

202

203 204 significance.

205

206

207

208

209

210

211

212

213 214 reliable question was "...Shortness of breath at rest". constraints. Participant characteristics are presented in Table 3.

\section{Test-retest Reliability of GAQ Items}

Of the 119 individuals presenting to the lab, 113 agreed to participate. None of the participants were excluded to participate based on the exclusion criteria listed earlier. Both study sessions were completed by 112 of the participants ( $99 \%$ completion rate). One participant did not complete the GAQ due to time

The following guidelines were adopted for interpreting the strength of agreement for $\kappa$ values and intraclass correlation coefficients (Landis and Koch, 1977): $<0.00$ represents poor agreement; 0.00 to 0.20 represents slight agreement; 0.21 to 0.4 represents fair agreement; 0.41 to 0.6 represents moderate agreement; 0.61 to 0.8 represents substantial agreement; $>0.80$ represents almost perfect agreement. While we did test for statistical significance at the $5 \%$ level, interpretation of results should be primarily focused on the magnitude of the coefficients, which demonstrate the strength of agreement, regardless of statistical

Test-retest reliability was only possible for eight of the nine items representing the "Preparing to Become More Active" questions on page one of the GAQ. There were no individuals who said 'yes' for the concussion question (1F) at visit one, thus it was not possible to calculate reliability for that item. Of the eight questions evaluated, there was substantial agreement for six of the questions and fair agreement for the other two (Table 4). All questions were statistically significant, testing at alpha $=0.05$ (i.e., for each question, the null hypothesis of $\kappa=0$ (no agreement) was rejected; all p-values were $<0.05$ ). The questions that were shown to be most reliable were: "Do you have any other medical condition that affects your ability to be physically active?”; “...Dizziness or light-headedness during physical activity?”; and "...Diagnosis of heart disease or stroke, or pain/discomfort/pressure in your chest during activities of daily living or during physical activity?". The least 
215 For the GAQ section on assessing current physical activity levels, intraclass correlation coefficients

216 (ICCS) were produced for reliability between the two visits (Table 3). For the question "On how many

217 days/week do you typically do moderate-to-vigorous-intensity aerobic physical activity?", there was almost

218 perfect agreement. The question "On days that you do at least moderate intensity aerobic physical activity, for

219 how many min do you do this activity?" had moderate agreement; and the third question, derived from the

220 first two questions, had agreement as expected, which was in-between perfect and moderate agreement (i.e.,

221 substantial agreement). According to participant self-completed physically activity levels, 78 participants (70\%)

222 were meeting Canada's Physical Activity Guidelines (mean: 3.4 days per week, mean: 55 minutes per day,

223 mean: 203 minutes per week).

224

Evidence for test-retest reliability was poor for the "Declaration" questions (Table 5). Questions

225 ranged from slight agreement $(\kappa=0.16)$ to substantial agreement $(\kappa=0.61)$, with three of the five questions

226 having kappa values in only the slight or fair agreement range.

227

Of the seven questions from the reference document that could be evaluated (Table 6) there was

228

perfect agreement for one question ("Loss of consciousness/fainting for any reason?"), where only one person

229 reported YES to that question (at both time points). There was almost perfect agreement for two questions,

230 substantial agreement for three questions, and moderate agreement for one question. All questions were

231 statistically significant, testing at alpha $=0.05$ (i.e., for each question, the null hypothesis of $\kappa=0$ (no

232 agreement) was rejected). The questions that showed almost perfect agreement were also two of the most

233 reliable items on page 1 (1A and 1C 'Diagnosis of cardiovascular disease or stroke or chest pain in activities of

234 daily living or during physical activity' and 'Dizziness or light-headedness during physical activity?') The least

235 reliable question from the reference document section was “...Any other medical condition that affects your

236 ability to be physically active?"

\section{Risk Assignment}


239 physical activity screening is presented in Table 7. Six participants screened themselves out, with 103 screening

240 themselves in. Based on the stress test criteria, 18 participants were 'screened out' and 91 were 'screened in';

241 thus, the prevalence of the outcome of interest, 'screening out' via stress test, was $16.5 \%$. Reasons for stress

242 test screen-outs are listed in Table 8.

243 Overall, the results indicate that the GAQ performs well in accurately screening older adults into physical

244 activity participation, but did not perform well in 'screening out'. Of the 18 individuals who were 'screened out'

245 via the stress test, only 1 individual was also 'screened out' using the GAQ. Specifically, the GAQ had low

246 sensitivity (0.06) but high specificity (0.95). Similarly, the GAQ had low positive predictive value (0.17) but high

247 negative predictive value (0.84). Lastly, the GAQ demonstrated low false positive probability at 0.05 (i.e., very

248 few individuals who were true negative responders ['screened in' via stress test] had a positive test result on

249 the GAQ ['screened out' via GAQ]), but high false negative probability at 0.94 (i.e., most individuals who were

250 true positive responders ['screened out' via stress test] had a negative test result on the GAQ ['screened in' via

251 GAQ]). The GAQ 'screened in' 18 of 19 participants, when in fact the objective measure or gold standard (i.e.,

252 the stress test) indicated that the individuals should not be. The accuracy or correct classification rate of the

$253 \mathrm{GAQ}$, that is proportion of observations for which the test result (GAQ) and gold standard (stress test) agree,

254 was $79.8 \%$.

\section{GAQ Item Validation}

For the evaluation of Question 1a from the GAQ, only chest pain as a reason for stopping the stress test

257 was used as the objective measure for evaluation since there were no individuals who had ECG changes as a

258 reason for having to stop. Due to the small number of cases arising from both the GAQ item ("A diagnosis of

259 heart disease or stroke, or pain/discomfort/pressure in your chest during activities of daily living or during

260 physical activity?") and the stress test criterion (chest pain as a reason for stopping the stress test), this

261 precluded the ability to calculate sensitivity or positive predictive value (see Table 8a). Both the specificity and 
262 negative predictive value were high at 0.95 and 0.99 , respectively. The false positive probability was low (0.05),

263 while the false negative probability was 1.0 (i.e., because there was only one individual who had chest pain

264 indicated as a reason for stopping the stress test and this individual did not indicate any chest pain on the

265 GAQ).

266

The GAQ item "A diagnosis of high blood pressure (BP) and/or a resting BP of 160/90 $\mathrm{mmHg}$ or

267 higher?" had low sensitivity (0.18) but high specificity (0.94). Both the positive predictive value and negative

268 predictive value were moderate at 0.67 and 0.62 , respectively. The false positive probability was low at 0.06

269 but the false negative probability was high at 0.82 (Table 9b).

\section{Discussion}

271 The newly developed GAQ was added to the yearly stress test procedures of adults attending older

272 adult physical activity programming in-order-to evaluate its effectiveness as a physical activity screening tool in

273 community-dwelling adults of the older adult age-range. The present sample of adults were relatively healthy,

274 independently living, and largely physically active. The psychometric properties of questionnaires are

275 population specific, as such the generalizability of the results is limited to that description. However, as

276 described below, the sample does have similar demographics as the Canadian older adult population. This

277 study was conducted in London, Ontario, which is categorized as a Census Metropolitan Area (CMA, population

278 greater than 100,000). According to the Portrait of Seniors in Canada 2006 report (Turcotte and Schellenberg,

279 2006), 70\% of Canadians aged 65 years and older live in CMAs or urban centres (populations greater than

$28050,000)$. The average age of the present sample was $75 \pm 7$ years. Among the 65 -year-and-older population in

281 Canada, $43 \%$ are males, versus $52 \%$ in the present sample. The present sample with a mean BMI of $26.5 \mathrm{~kg} / \mathrm{m}^{2}$

282 would be categorized as overweight. However, from the 2008 Statistics Canada report on the estimates of

283 obesity among of Canadian Adults (Government of Canada, 2008), the mean BMI of the adult population aged

28465 to 79 years is $28 \mathrm{~kg} / \mathrm{m}^{2}$. In the Canadian population, $76 \%$ of Seniors report having at least one chronic

285 condition (Statistics Canada 2008). In the present sample, 72\% reported having at least one chronic condition.

286 The vast majority of older adults who participated in this study engaged in community-based physical activity 
287 programming, similar to previous work in physical activity assessments (Davis et al., 2001). Due to the relatively

288 healthy sample, this group may not necessarily be representative of the major chronic conditions reported by

289 older Canadians (e.g. heart disease and cancers). However, hypertension and arthritis are the top two

290 conditions reported by older Canadians (Canadian Institute for Health Information, 2011), similar to the

291 present study sample. Based on mean MMSE and MoCA scores, the present sample had no cognitive

292 impairments. Although, $20 \%$ of a subset of the sample (15/76) did self-report having memory complaints.

293

A majority of the self-completed GAQ screening questions demonstrate acceptable test-retest

294 reliability over a one-week period. Of the eight questions evaluated from page one of the GAQ (that is all of the

295 "Prepare to Become More Active" questions 1A-1F, 2, 3, 4), there was substantial agreement for six of the

296 questions and fair agreement for the other two questions. The prevalence of some of the conditions/symptoms

297 the GAQ seeks to screen for were low in the present sample and thus the non-variance for the dichotomous

298 variables may have influenced the questions for which the test-retest reliability was lower. In addition, while

299 the short time between administrations sought to minimize the occurrence of any adverse events or new

300 diagnoses, the process of recall may have influenced the reported reliability estimates; as many participants

301 would tell the research assistant that in the week following visit one, their memory was jarred to potentially

302 relevant issues. The responses for how many times per week the older adults participate in physical activity

303 were very reliable. However, the responses to how many minutes of physical activity was engaged in per those

304 physically active days were less reliable. Based on feedback from participants and clarifications asked of the

305 research assistant, the participants often indicated slight changes in their physical activity routines between

306 the week prior to visit one and the subsequent week (visit two); and this often led to difficulty in understanding

307 what to report and may have impacted the variability of the responses. Of the declaration options, the only

308 option with substantial agreement was "I answered NO to all questions". The remainder of the questions

309 demonstrated slight to moderate agreement between the two test sessions. This may have been influenced by

310 the unfamiliarity of the terms used in the questions (for example QEP), the number of and detail of the options,

311 and some indication from feedback that the "Check All That Apply" instruction was often missed. In addition, 
312 because a significant percentage of the present sample was already active, they may have had difficulty in 313 completing this section.

314 The validity of physical activity screening tools is based on its accuracy in 'screening in' low risk

315 individuals and 'screening-out' high risk individuals. The present stress testing protocol allowed for the 316 objective validation of two of the "Prepare to Become More Active" items, namely 1A and 1B. Again, for the 317 item "A diagnosis of heart disease or stroke, or pain/discomfort/pressure in your chest during activities of daily 318 living or during physical activity?", sensitivity could not be calculated due to small numbers. However, the false 319 negative probability would suggest that this GAQ item did not correlate with individuals who experienced chest 320 pain during the graded treadmill stress test. However, it should be noted that it is possible that the stress test 321 identified a previously undiagnosed condition and the self-reported chest pain may have not been related to 322 cardiovascular disease (for example, musculoskeletal chest wall pain). Alternatively, the specificity was high for 323 this item. The validity of GAQ blood pressure question had low validity; that is the self-reporting of high blood 324 pressure was in conflict with the objective measures taken during the stress test (i.e. low sensitivity). The 325 participant responses may have been influenced by the common issue related to self-identification to the 326 presence of a chronic disease which is being treated with medication. That is, if the medication normalizes 327 blood pressure, some participants may have checked "No"; but the objective criteria included blood pressure 328 medications as an indication of having high blood pressure. It is also unknown if this sample properly 329 understood the second option of the questions, that is, "and/or a resting blood pressure of $>160 \mathrm{mmHg}$ or 330 greater".

331 The GAQ is intended to prospectively assign physical activity participants to risk levels (that is, 332 appropriately 'screen-in' / 'screen out'). In the present sample (with responses by relatively healthy older 333 adults), the self-completion of the GAQ had poor risk assessment sensitivity when compared with the treadmill 334 stress test. This was supported by a poor positive predictive value and poor false negative probability. 335 However, consistent with reliability and item validity, the GAQ had good risk assessment specificity. Part of the 336 impetus for the development of GAQ was the issue of false positives with previous physical activity screening 
337 tools (Cardinal et al., 1996). In a relatively healthy older adult sample completing the GAQ in the present

338 investigation, the false positives were low- however, the false negatives were high. These results should be

339 considered in light of the relatively low rates of high risk participants in the sample. In addition, the results are

340 dependent on our criteria for 'screen in and out'; largely influenced by the declaration questions, which did not

341 have strong psychometric properties in this population. The authors report no conflicts of interest associated

342 with this manuscript.

\section{Conclusions}

344 The GAQ reduced false positive findings in an active, community-dwelling older adult population.

345 Unfortunately, the present sample had a high rate of false negative results. Although the GAQ 'screens in'

346 many older adults to safely proceed and participate in physical activity, it does not 'screen out' individuals with

347 the same accuracy as the gold-standard stress test. Next steps include: obtaining a larger sample of older

348 adults, excluding questions identified as challenging or without a corresponding question in the standard stress

349 test data collection form, or changing the format of the GAQ. As well, long term data collection post-

350 questionnaire completion of those 'screened in' by the GAQ could provide evidence that may contribute to the 351 understanding of the practical and real-world impact the GAQ has in an older adult population.

\section{Acknowledgements}

353 The authors would like to thank Ashleigh de Cruz, Cassandra Bartol, and Narlon Cassio Boa Sorte Silva for their 354 assistance throughout this project with data collection and analysis. Additionally, the authors would like to 355 thank the Canadian Society for Exercise Physiology for funding to support this project. 
363 Bloodpressureuk.org., n.d. Blood Pressure: Blood pressure chart. Found at

364 http://www.bloodpressureuk.org/BloodPressureandyou/Thebasics/Bloodpressurechart

365 Canadian Institute for Health Information. 2011. Health Care in Canada, 2011: A Focus on Seniors Care and $366 \quad$ Aging. Ottawa: ClHI.

367 Cardinal, B.J., Esters, J., and Cardinal, M.K. 1996. Evaluation of the revised physical activity readiness questionnaire in older adults. Med. Sci. Sports. Exerc. 28(4): 468-472. doi:10.1097/00005768$199604000-00011$

370 Chodzko-Zajko, W.J., Proctor, D.N., Fiatarone Singh, M.A., Minson, C.T., Nigg, C.R., Salem, G.J., et al. 2009.

371

372

373

374

375

376

377

378

379

380

381

382 American College of Sports Medicine. American College of Sports Medicine Position Stand: Exercise and physical activity for older adults. Med. Sci. Sports. Exerc. 41(7): 1510-1530. doi:10.1249/MSS.0b013e3181a0c95c

Cohen, J. 1960. A coefficient of agreement for nominal scales. Educ. Psychol. Meas. 20(1):37-46. doi:10.1177/001316446002000104

Davis, H.S., MacPherson, K., Merry, H.R., Wentzel, C., and Rockwood, K. 2001. Reliability and validity of questions about exercise in the Canadian Study of Health and Aging. Int. Psychogeriatr. 13(Suppl. 1): 177-182.

Doma, K., Speyer, R., Leicht, A. S., and Cordier, R. 2017. Comparison of psychometric properties between usualweek and past-week self-reported physical activity questionnaires: a systematic review. Int. J. Behav. Nutr. Phys. Act. 14(10): 1-28. doi:10.1186/s12966-017-0470-6

Donner, A., and Zou, G. 2002. Testing the equality of dependent intraclass correlation coefficients. Journal of the Royal Statistical Society Series D: The Statistician. Blackwell Publishers, 51(3):367-79. 
384 Eves, N.D., and Davidson, W.J. 2011. Evidence-based risk assessment and recommendations for physical 385 activity clearance: respiratory disease. Appl. Physiol. Nutr. Metab. 36(Suppl. 1): S80-100. doi:

386 10.1139/h11-057.

387

Forsen, L., Loland, N.W., Vuillemin, A., Chinapaw, M.J., van Poppel, M.N., Mokkink, L.B., et al. 2010. Self-

388 administered physical activity questionnaires for the elderly: a systematic review of measurement

389 properties. Sports. Med. 40(7): 601-23. doi:10.2165/11531350-000000000-00000.

390

Gill, T. M., DiPietro, L., and Krumholz, H.M. 2000. Role of Exercise Stress Testing and Safety Monitoring for 391 Older Persons Starting an Exercise Program. JAMA, 284(3): 342-9.

392

Gilmour, H., and Park, J. 2006. Dependency, chronic conditions and pain in seniors. Health Reports 2006.16

393 Suppl.: 21-31.

394

Goodman, J.M., Burr, J.F., Banks, L., and Thomas, S.G. 2016. The Acute Risks of Exercise in Apparently Healthy Adults and Relevance for Prevention of Cardiovascular Events. Can. J. Cardiol. 32(4): 523-32. doi:

396 10.1016/j.cjca.2016.01.019.

397

Government of Canada. 2008. The Chief Public Health Officer's Report on the State of Public Health in Canada

398 2008: Addressing Health Inequalities. http://www.phac-aspc.gc.ca/cphorsphc-respcacsp/2008/fr-

399 rc/pdf/CPHO-Report-e.pdf

400

Koepsell, T.D., and Weiss, N.S. 2003. Epidemiologic Methods - Studying the Occurrence of Illness. New York:

401 Oxford University Press.

402 Lafountain, R.A., Serafim da Silveira, J., Varghese, J., Mihai, G., Scandling, D., Craft, J., et al. 2016.

403 Cardiopulmonary exercise testing in the MRI environment. Physiol. Meas. 37(4): N11-25.

404 doi:10.1088/0967-3334/37/4/N11. 
405 Landis, J.R., and Koch, G.G. 1977. The Measurement of Observer Agreement for Categorical Data. Biometrics. 33(1): 159-74.

407 Morey, M. C., and Sullivan, R. J. 2003. Medical assessment for health advocacy and practical strategies for 408 exercise initiation. Am. J. Prev. Med. 25(3 Suppl 2): 204-08. doi:10.1016/S0749-3797(03)00180-6.

409 Nelson, M. E., Rejeski, W. J., Blair, S. N., Duncan, P. W., Judge, J. O., King, C.A., et al. 2007. Physical activity and 410 public health in older adults: Recommendation from the American College of Sports Medicine and the American Heart Association. Circulation, 116(9): 1094-1105.

412 doi:10.1161/CIRCULATIONAHA.107.185650

413 Petrella, R.J., and Wight, D. 2000. An office-based instrument for exercise counseling and prescription in 414 primary care. The Step Test Exercise Prescription (STEP). Arch. Fam. Med. 9(4): 339-44.

415 doi:10.1001/archfami.9.4.339

416 Resnick, B., Ory, M., Coday, M., and Riebe, D. 2008. Professional perspectives on physical activity screening 417 practices: Shifting the paradigm. Crit. Public. Health. 18(1): 21-32. doi:10.1080/09581590701771717.

418 Riebe, D., Franklin, B.A., Thompson, P.D., Garber, C.E., and Whitfield, G.P. 2015. Updating ACSM's

419 recommendations for exercise pre-participation health screening. Med. Sci. Sports. Exerc. 47(11): 2473-2479. doi:10.1249/MSS.0000000000000664

421 SAS Institute Inc 2013. SAS/ACCESS ${ }^{\circledR} 9.4$ Interface to ADABAS: Reference. Cary, NC: SAS Institute Inc.

422 Statistics Canada Health Report. Canada at a Glance 2008. https://www45.statcan.gc.ca/2008/cgco_2008_000$423 \quad$ eng.htm

424 Streiner, D.L., and Norman, G.R. 1995. Measurement Scales: A Practical Guide to Their Development and Use 425 (2 ${ }^{\text {nd }}$ ed.). Oxford: Oxford University Press. pp. 104-127. 
426 Turcotte M., and Schellenberg G. 2006. A Portrait of Seniors in Canada. Statistics Canada. 2006001. Ottawa: 427 Statistics Canada.

428 Get Active Questionnaire found at http://www.csep.ca/home

429

430 
Table 1. Test-retest Reliability of the "Assess Your Current Physical Activity" Questions

\begin{tabular}{|l|c|c|c|}
\hline Question & $\mathrm{N}$ & ICC (95\% Confidence Interval) & P value \\
\hline Days/Wk $^{\mathrm{a}}$ & 107 & $0.81(0.73$ to 0.87$) ;$ almost perfect & $\mathrm{p}<0.001$ \\
\hline Min/Day $^{\mathrm{a}}$ & 108 & $0.51(0.37$ to 0.64$) ;$ moderate agreement & $\mathrm{p}<0.001$ \\
\hline Min/Wk $^{\mathrm{a}}$ & 107 & $0.64(0.51$ to 0.74$) ;$ substantial agreement & $\mathrm{p}<0.001$ \\
\hline
\end{tabular}

432 ICC = intraclass correlation coefficient

$433{ }^{a}$ Refers to at least moderate-intensity aerobic physical activity

434

435

436

437

438

439

440

441

442

443

444

445

446

447

448

449

450

451

452 
Table 2. Stress-Test Derived Screening

\begin{tabular}{|l|l|l|l|}
\hline & \multicolumn{2}{|l|}{ Stress-Test Derived Screening } & \\
\hline Self-screen via GAQ & + (Screen OUT) & - (Screen IN) & \\
\hline$+($ Screen OUT) & a & b & a+b \\
\hline$-($ Screen IN) & c & d & c+d \\
\hline & a+c & b+d & N \\
\hline
\end{tabular}

454

1. Sensitivity (SN): Calculated as a / $(\mathrm{a}+\mathrm{c})$. This value answers the question: "When GAQ is truly positive (i.e., stress test = 'Screen out'), how often does the GAQ detect this?"

2. Specificity (SP): Calculated as $d /(b+d)$. This value answers the question: "When a stress test is truly negative (i.e., stress test = 'Screen in'), how often does the GAQ detect this?"

3. Positive Predictive Value (PPV): Calculated as a / $(a+b)$. This value answers the question: "If the result of the GAQ screen is positive (i.e., 'Screen out'), how likely is it that the person would actually screen positive (i.e. 'Screen out') via the stress test?" Note: this depends on SN, SP and on the prevalence of the outcome of interest (i.e., stress test screen out) and low prevalence will lead to a poorer PPV.

4. Negative Predictive Value (NPV): Calculated as $=d(c+d)$. This value answers the question: "If the result of a GAQ screen is negative (i.e., 'Screen in'), how likely is it that the person would actually screen negative (i.e., 'Screen in') via the stress test?"

5. False positive probability: Calculated as $b /(b+d)$ and defined as the proportion of true negative responders that have a positive test result for the GAQ.

6. False negative probability: Calculated as $c /(a+c)$ and defined as the proportion of true positive responders that have a negative test result for the GAQ. of observations for which the stress test results and actual response on the GAQ agree. 
Table 3. Subject Characteristics

\begin{tabular}{|c|c|c|}
\hline Variables & $\mathbf{n}$ & Mean \pm SD \\
\hline \multicolumn{3}{|l|}{ Sex } \\
\hline Male & $58(52 \%)$ & \\
\hline Female & $54(48 \%)$ & \\
\hline Age & & $75 \pm 7$ years \\
\hline $50-54$ & 0 & \\
\hline $55-59$ & $2(2 \%)$ & \\
\hline $60-64$ & $4(4 \%)$ & \\
\hline $65-69$ & $15(13 \%)$ & \\
\hline $70-74$ & $36(32 \%)$ & \\
\hline $75-79$ & $27(24 \%)$ & \\
\hline $80-84$ & $16(14 \%)$ & \\
\hline $85-89$ & $8(7 \%)$ & \\
\hline $90+$ & $4(4 \%)$ & \\
\hline BMI & 111 & $26.5 \pm 3.9 \mathrm{~kg} / \mathrm{m}^{2}$ \\
\hline \multicolumn{3}{|l|}{ Currently Exercising (Self-report) } \\
\hline Yes & $105(94 \%)$ & \\
\hline No & $6(6 \%)$ & \\
\hline \multicolumn{3}{|l|}{ Current Smoker } \\
\hline Yes & $6(6 \%)$ & \\
\hline No & $99(94 \%)$ & \\
\hline Self-Reported Health Conditions & 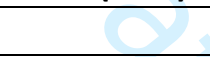 & \\
\hline \multicolumn{3}{|l|}{ High Cholesterol } \\
\hline Yes & $49(44 \%)$ & \\
\hline No & $62(56 \%)$ & \\
\hline \multicolumn{3}{|l|}{ High Blood Pressure } \\
\hline Yes & $42(38 \%)$ & \\
\hline No & $69(62 \%)$ & \\
\hline \multicolumn{3}{|l|}{ Heart Problems } \\
\hline Yes & $7(6 \%)$ & \\
\hline No & $103(94 \%)$ & \\
\hline \multicolumn{3}{|l|}{ Type II Diabetes } \\
\hline Yes & $8(7 \%)$ & \\
\hline No & $103(93 \%)$ & \\
\hline \multicolumn{3}{|l|}{ Lung Problems } \\
\hline Yes & $11(10 \%)$ & \\
\hline No & $100(90 \%)$ & \\
\hline \multicolumn{3}{|l|}{ Joint Problems } \\
\hline Yes & $39(35 \%)$ & \\
\hline No & $71(65 \%)$ & \\
\hline MoCA (/30) & 98 & $26 \pm 3$ \\
\hline MMSE (/30) & 100 & $29 \pm 1$ \\
\hline
\end{tabular}


Table 4. Test-retest Reliability of the "Prepare to Become More Active" Questions ${ }^{a}$

\section{7}

\begin{tabular}{|c|c|c|c|c|c|}
\hline Question & N & $\begin{array}{c}\text { Frequency (visit 1) } \\
\text { "No" }\end{array}$ & $\begin{array}{c}\text { Frequency (visit 1) } \\
\text { "Yes" }\end{array}$ & $\begin{array}{c}\text { Kappa (95\% Confidence } \\
\text { Interval) }\end{array}$ & P value \\
\hline 1a & 109 & 103 & 6 & $\begin{array}{c}0.75(0.49 \text { to 1.00); } \\
\text { substantial agreement }\end{array}$ & $p<0.001$ \\
\hline 1b & 108 & 96 & 12 & $\begin{array}{c}0.70(0.47 \text { to 0.92); } \\
\text { substantial agreement }\end{array}$ & $p<0.001$ \\
\hline 1c & 110 & 98 & 12 & $\begin{array}{c}0.76(0.55 \text { to 0.96); } \\
\text { substantial agreement }\end{array}$ & $p<0.001$ \\
\hline 1d & 109 & 104 & 5 & $\begin{array}{c}0.32(-0.16 \text { to } 0.80) ; \\
\text { fair agreement }\end{array}$ & $\begin{array}{c}p= \\
0.046\end{array}$ \\
\hline 1e & 109 & 106 & 3 & $\begin{array}{c}0.49(-0.11 \text { to } 1.00) ; \\
\text { fair agreement }\end{array}$ & $p=0.03$ \\
\hline 1f & 109 & 108 & 1 & $\begin{array}{c}0.72(0.54 \text { to } 0.90) ; \\
\text { substantial agreement }\end{array}$ & $p<0.001$ \\
\hline 2 & 108 & 90 & 18 & $\begin{array}{c}0.64(0.35 \text { to 0.93); } \\
\text { substantial agreement }\end{array}$ & $p<0.001$ \\
\hline 3 & 110 & 103 & 7 & $\begin{array}{c}0.76(0.53 \text { to } 0.99) ; \\
\text { substantial agreement }\end{array}$ & $p<0.001$ \\
\hline 4 & 108 & 99 & 9 & & \\
\hline
\end{tabular}

\footnotetext{
${ }^{\mathrm{a}}$ From page 1 of the GAQ
}

478

479

480

481

482

483

484

485

486 
Table 5. Test-retest Reliability of the "Declaration" Questions

\begin{tabular}{|l|c|c|c|c|c|}
\hline Question & N & \multicolumn{2}{|c|}{ Frequency (Visit 1) } & Kappa (95\% Confidence Interval) & P value \\
\cline { 3 - 4 } & & Not Checked & Checked & & \\
\hline $1^{\text {a }}$ & 107 & 54 & 53 & $0.61(0.46$ to 0.76); substantial agreement & $p<0.001$ \\
\hline $2^{\text {b }}$ & 107 & 85 & 22 & $0.35(0.14$ to 0.57$) ;$ fair agreement & $p<0.001$ \\
\hline $3^{\text {c }}$ & 107 & 83 & 24 & $0.45(0.24$ to 0.67$) ;$ moderate agreement & $p<0.001$ \\
\hline $4^{\text {d }}$ & 107 & 25 & 82 & $0.16(-0.04$ to 0.36$) ;$ slight agreement & $p=0.12$ \\
\hline $5^{\text {e }}$ & 107 & 89 & 18 & $0.23(-0.01$ to 0.47$) ;$ fair agreement & $p=0.03$ \\
\hline
\end{tabular}

489

a "I answered NO to all questions"

490 ' "I answered YES to any question and I have consulted a HCP and/or QEP who has recommended that I

491 become more physically active"

492 " "I answered YES to any question and I have not consulted a HCP and/or QEP about becoming more physically

493 active"

494 "I am comfortable with becoming more physically active on my own without consulting a HCP or QEP"

495 e "I would like to consult a QEP about becoming more physically active"

496

497

498

499

500

501

502

503

504 
505 Table 6. Test-retest Reliability of the "Reference Document" Questions

\begin{tabular}{|l|c|c|c|c|c|}
\hline \multirow{2}{*}{ Question } & \multirow{2}{*}{$\mathrm{N}$} & \multicolumn{2}{|c|}{ Frequency (Visit 1) } & \multirow{2}{*}{ Kappa (95\% Confidence Interval) } & P value \\
\cline { 3 - 5 } & & $\begin{array}{c}\text { Not } \\
\text { Checked }\end{array}$ & Checked & & \\
\hline 1a & 108 & 103 & 5 & $0.90(0.72$ to 1.00$) ;$ almost perfect & $p<0.001$ \\
\hline 1b & 108 & 98 & 10 & $0.73(0.48$ to 0.98$) ;$ substantial agreement & $p<0.001$ \\
\hline 1c & 108 & 99 & 9 & $0.87(0.68$ to 1.00$) ;$ almost perfect & $p<0.001$ \\
\hline 1d & 108 & 104 & 4 & -- & - \\
\hline 1e & 108 & 107 & 1 & $1.0(1.0$ to 1.0$) ;$ perfect agreement & $p=0.01$ \\
\hline 1f & 108 & 108 & 0 & -- & - \\
\hline 2 & 105 & 88 & 17 & $0.61(0.39$ to 0.83$) ;$ substantial agreement & $p<0.001$ \\
\hline 3 & 105 & 98 & 7 & $0.64(0.35$ to 0.93$) ;$ substantial agreement & $p<0.001$ \\
\hline 4 & 105 & 97 & 8 & $0.46(0.14$ to 0.78$) ;$ moderate agreement & $p<0.001$ \\
\hline
\end{tabular}

506

507 
Table 7. Risk Assignment for Self- and Objective Screening for Physical Activity

509

\begin{tabular}{|c|c|c|c|}
\hline \multirow{2}{*}{\begin{tabular}{|l}
\multicolumn{2}{|c|}{ Self-screening for PA } \\
Frequency
\end{tabular}} & \multicolumn{3}{|c|}{ Stress Test Screening for PA } \\
\hline & Screen OUT & Screen IN & \\
\hline Row Pct & (No PA) & (Yes PA) & \\
\hline Col Pct & + & - & Total \\
\hline \multirow[t]{2}{*}{ Screen OUT (No PA) } & $1^{* *}$ & 5 & 6 \\
\hline & $16.67 \ddagger$ & 83.33 & 5.50 \\
\hline \multirow[t]{2}{*}{+} & $5.56 *$ & 5.49|| & \\
\hline & $a(T P)$ & $b(F P)$ & \\
\hline \multirow[t]{2}{*}{ Screen IN (Yes PA) } & 17 & $86^{* *}$ & 103 \\
\hline & 16.50 & $83.50 \S$ & 94.50 \\
\hline \multirow[t]{2}{*}{-} & 94.44 & $94.51 \dagger$ & \\
\hline & $c(F N)$ & $d(T N)$ & \\
\hline \multirow[t]{2}{*}{ Total } & 18 & 91 & $109 * *$ \\
\hline & 16.51 & 83.49 & 100.00 \\
\hline \multicolumn{4}{|c|}{ Frequency Missing = 3} \\
\hline
\end{tabular}

510

Notes:

$511 \mathrm{TP}=$ True positives; FP = False Positives; FN = False Negatives; $\mathrm{TN}=$ True Negatives.

$512 *$ Sensitivity (SN) $=a /(a+c)$

513 tSpecificity (SP) $=\mathrm{d} /(\mathrm{b}+\mathrm{d})$

$514 \quad+$ Positive Predictive Value (PPV) $=\mathrm{a} /(\mathrm{a}+\mathrm{b})$

515 §Negative Predictive Value (NPV): = d / $(c+d)$

516 | False positive probability $=b /(b+d)$

517 ๆFalse negative probability $=\mathrm{c}(\mathrm{a}+\mathrm{c})$

$518 * *$ Accuracy/correct classification rate $=(\mathrm{a}+\mathrm{d}) / \mathrm{N}$

519 
520 Table 8. List of Reasons for Objective Screen-outs

\begin{tabular}{|l|c|}
\hline Reason for Screen Out & $\mathrm{n}^{*}$ \\
\hline Stress Test Impressions & $\mathbf{8}$ \\
\hline $\begin{array}{l}\text { Reason for stopping stress test: Light- } \\
\text { headedness/Dizziness }\end{array}$ & $\mathbf{1}$ \\
\hline Reason for stopping stress test: Chest Pain & 1 \\
\hline $\begin{array}{l}\text { Reported heart problems (i.e., Chest } \\
\text { Pain/Tightness/Angina) }\end{array}$ & 7 \\
\hline $\begin{array}{l}\text { Hypotension (SBP<100 and/or DBP <60 mmHg via } \\
\text { any measurements during stress test) }\end{array}$ & 4 \\
\hline
\end{tabular}

$521{ }^{*}$ Combined numbers are greater than the total number of objective screen-outs $(n=19)$ because some

522 individuals had more than one of the above reasons per why they were classified as an objective screen-out.

523

524

525

526

527

528

529

530

531

532

533

534

535 
Table 9a. Item Validity for Question 1A “A diagnosis of heart disease or stroke, or pain/discomfort/pressure

537 in your chest during activities of daily living or during physical activity?"

\begin{tabular}{|c|c|c|c|}
\hline \begin{tabular}{|} 
Q1A0(GAQ-Dx of CVD or \\
stroke OR chest \\
pain/discomfort/pressure \\
(past 6 months)
\end{tabular} & \multicolumn{3}{|c|}{$\begin{array}{c}\text { Chest pain -Reason for Stopping } \\
\text { Stress Test }\end{array}$} \\
\hline Frequency & \multirow{3}{*}{$\begin{array}{r}\text { Yes } \\
+\end{array}$} & \multirow{3}{*}{$\begin{array}{r}\text { No } \\
-\end{array}$} & \multirow[b]{3}{*}{ Total } \\
\hline Row Pct & & & \\
\hline Col Pct & & & \\
\hline Yes & $\begin{array}{r}0 \\
0.00\end{array}$ & $\begin{array}{r}5 \\
100.00\end{array}$ & \multirow[t]{2}{*}{$\begin{array}{r}5 \\
4.81\end{array}$} \\
\hline+ & $\begin{array}{r}0.00 \\
a(T P)\end{array}$ & $\begin{array}{l}4.85 \ddagger \\
b(F P)\end{array}$ & \\
\hline No & $\begin{array}{r}1 \\
1.01\end{array}$ & $\begin{array}{r}98 \\
98.99+\end{array}$ & \multirow[t]{2}{*}{$\begin{array}{r}99 \\
95.19\end{array}$} \\
\hline- & $\begin{array}{r}100.00 \\
c(F N)\end{array}$ & $\begin{array}{r}95.15^{*} \\
d(T N)\end{array}$ & \\
\hline Total & $\begin{array}{r}1 \\
0.96\end{array}$ & $\begin{array}{r}103 \\
99.04\end{array}$ & $\begin{array}{r}104 \\
100.00\end{array}$ \\
\hline \multicolumn{4}{|c|}{ Frequency Missing = 8} \\
\hline
\end{tabular}

538 Notes:

$539 \mathrm{TP}=$ True positives; FP = False Positives; FN = False Negatives; $T N=$ True Negatives.

$540 *$ Specificity (SP) $=\mathrm{d} /(\mathrm{b}+\mathrm{d})$

541 tNegative Predictive Value (NPV): $=d /(c+d)$

$542 \quad$ False positive probability $=\mathrm{b} /(\mathrm{b}+\mathrm{d})$

543 §False negative probability $=c(a+c)$

544

545

546

547

548

549

550 
551 Table 9b. Item Validation for Q1B “A diagnosis of high blood pressure (BP) and/or a resting BP of 160/90 552 mmHg or higher?"

\begin{tabular}{|c|c|c|c|}
\hline $\begin{array}{c}\text { Q1B(GAQ-T0:Dx } \\
\text { high BP/rest BP } \\
>=160 / 90 \text { (past } 6 \\
\text { mo)) }\end{array}$ & \multicolumn{3}{|c|}{$\begin{array}{l}\text { Stress T Derived - High BP } \\
\text { ( }>=160 / 90 \mathrm{mmHg} \text { resting } \\
\text { measured OR on BP meds) }\end{array}$} \\
\hline Frequency & \multirow{3}{*}{$\begin{array}{r}\text { Yes } \\
+\end{array}$} & \multirow{3}{*}{$\begin{array}{r}\text { No } \\
-\end{array}$} & \multirow[b]{3}{*}{ Tota } \\
\hline Row Pct & & & \\
\hline Col Pct & & & \\
\hline Yes & $\begin{array}{r}8 \\
66.67 \ddagger\end{array}$ & $\begin{array}{r}4 \\
33.33\end{array}$ & $\begin{array}{r}12 \\
11.01\end{array}$ \\
\hline+ & $\begin{array}{r}17.78 * \\
a(T P)\end{array}$ & $\begin{array}{c}6.25|| \\
b(F P)\end{array}$ & \\
\hline No & $\begin{array}{r}37 \\
38.14\end{array}$ & $\begin{array}{r}60 \\
61.86 \S\end{array}$ & $\begin{array}{r}97 \\
88.99\end{array}$ \\
\hline- & $\begin{array}{r}82.22 \\
c(F N)\end{array}$ & $\begin{array}{r}93.75+ \\
d(T N)\end{array}$ & \\
\hline Total & $\begin{array}{r}45 \\
41.28\end{array}$ & $\begin{array}{r}64 \\
58.72\end{array}$ & $\begin{array}{r}109 \\
100.00\end{array}$ \\
\hline \multicolumn{4}{|c|}{ Frequency Missing = 3} \\
\hline
\end{tabular}

553

554 Notes:

$555 \mathrm{TP}=$ True positives; FP = False Positives; FN = False Negatives; $\mathrm{TN}=$ True Negatives.

$556 *$ Sensitivity $(\mathrm{SN})=\mathrm{a} /(\mathrm{a}+\mathrm{c})$

$557 \quad$ Specificity $(S P)=d /(b+d)$

$558 \quad$ Positive Predictive Value (PPV) $=\mathrm{a} /(\mathrm{a}+\mathrm{b})$

559 §Negative Predictive Value (NPV): $=d /(c+d)$

560 || False positive probability = b / $(b+d)$

561 False negative probability $=\mathrm{c}(\mathrm{a}+\mathrm{c})$

562 